\title{
Effect of Globe Game on Students Achievement and Retention in Longitude and Latitude
}

\author{
Ndukwe Oji Nnachi Julius Ongele Ugama \\ Department of Science Education, Faculty of Education, \\ Ebonyi State University, Ishieke Campus, Abakaliki - Nigeria
}

\begin{abstract}
This study was designed to determine the effect of globe game on students' achievement and retention in longitude and latitude. To carry out the study, three research questions and three null hypotheses were formulated. Design for the study was a quasi-experimental non-equivalent control group's pre-test and post-test design. The sample for this study comprised of Two hundred and eighty four S S11 students. Six secondary schools were drawn through a stratified random sampling technique. Three schools (one male, one female and one co-educational) were assigned to the treatment group while the remaining three schools were assigned to the control group. The treatment group was taught longitude and latitude using the globe game approach while the control group was taught longitude and latitude using the conventional method. Longitude and Latitude Achievement Test was used to collect data on the achievement and retention of students. Research questions were answered using mean and standard deviation while hypotheses were tested using the Analysis of covariance (ANCOVA) at an alpha level of 0.05. The result revealed that globe game approach is superior to the conventional method in facilitating achievement and retention in longitude and latitude, but there was no significant interaction between gender and instructional method on students' achievement and retention in longitude and latitude. The researcher therefore, recommended that globe game approach should be used in secondary school system.
\end{abstract}

Keywords: Globe game, Longitude, Latitude and Retention.

DOI: $10.7176 / \mathrm{JEP} / 10-32-03$

Publication date: November $30^{\text {th }} 2019$

\subsection{Introduction}

Many students' hate to see figures and more often than not it is translated into their inability to handle figures effectively. This becomes more serious when the figure to be handled is not about buying and selling but about abstract areas like longitude and latitude in geometry. Longitude and latitude is an integral part of geometry which deals with the study of imaginary lines of the sphere Paulina (2015). Nigerian Educational Research and Development Council (NERDC, 2015), observed that difficult concepts in mathematics refer to any concept that pose challenges to teachers and learners and concluded that longitude and latitude are among the very difficult topics which students find difficult to comprehend. This study aimed at unraveling solution to this difficult mathematics concept through game.

The WAEC Chief Examiners Report (2016), suggested that students' performance in mathematics could be improved through meaningful and proper teaching. According to the report, teachers should help students develop in mathematics by reducing the abstractness of mathematics, and hence remove their apathy and fear of the subject. By the use of instructional materials for active learning the cognitive, affective and psychomotor domains of the learners are collectively and simultaneously developed. One of such instructional approach is the mathematical game approach.

A game is regarded as Mathematical when the players can perceive and/or influence the course of the game on the basis of Mathematical considerations Agwagah (2001). She further evaluated the effectiveness of mathematical games. Among the reasons are the tools for learning mathematics, learning mathematics by so doing, reduce tension, minimize boredom and encourage acquisition of knowledge and skills, practical application and systematic drill that are necessary for acquiring mathematical knowledge and skills, Games are also valuable for encouraging social skill, for stimulating mathematical discussion, helping the development of mathematical understanding, for developing strategies, for learning new concepts, reinforcing skills and concepts as aid to symbolization and logic Oldfield (2015).

Mathematical games can take the form of puzzles, magic tricks, fallacies, paradoxes or any type of mathematics which provides amusement or curiosity Dotun (2015). They bring joy to the learner, breakdown resistance to learning by reducing tension, clearing boredom and providing an environment where the students can develop skills and acquire more knowledge. They also stimulate mathematical thinking and generate excitement and spirit of individualism, cooperation and competition. Educators and researchers have recommended the use of educational games in teaching and learning of mathematics because it is found to sustain and develop students' achievement and retention in mathematics.

Retention has been described as the process of maintaining the availability of a replica of the acquired new 
means or repeat performance by a learner with an acquired piece of knowledge Nneji (2010). It refers to skill or knowledge or competences a learner acquired and retained from a learning situation after forgetting has taken place Ezeano (2013). It is the capacity to remember something, skills, knowledge, habits, attitudes or other responses initially acquired. Retention plays an important role for what is learned to be effectively applied. The teacher is usually faced with the task of how to help students improve on their ability to assimilate and retain what they have learnt.

Ugwuanyi (2014), cited that students' poor retention in mathematics could not be unconnected with rote learning that is prevalent in schools. However, mathematics concepts cannot be learnt properly by mere memorization as human beings have limited capacity for memorization. This kind of learning is still observable now especially in primary school pupil where a pupil can learn multiplication table from $2 \times 1$ to $12 \times 12$ through rote leaning. He/she can stand up and recite correctly all of them from beginning to the end. But when an independent question is asked say $8 \times 7$, the pupil may not get the answer easily rather he/she start from $8 \times 1$ to meet up with $8 \times 7$ before a correct answer could be given. This is due to the fact that he/she does not know the how and why $8 \times 7$ will give 56 .

Enough explanation with practical examples should be given to these students to bring out how and why of certain solutions of mathematics concepts so as to boast their retentive ability. This is also applicable to secondary school students when they learn about formulae and their applications in solving problems. The derivation of the formular should be exposed to them so that they can understand why the formular is, as it is. According to Nicol (2014) a teacher can only be effective, if the students can learn with greater ease and perform well with his help than without his help. So, retention which is the ability to reproduce the learnt concept when the need arises has been researched by many researchers. However, Ezeamenyi (2012), found that students' interests and retention could be aroused and retained through the use of appropriate instructional materials like games. The students with learning disabilities retained what they had learned in Mathematics several weeks after instruction, when exposed to game approach.

Gender issues have been linked with performance of students in academic tasks in several studies but without any definite conclusion. Some studies revealed that male students performed better than females in mathematics Odo (2012). In a similar report, WAEC (2011), chief examiners' reports confirmed that boys performed better than girls in mathematics. However, Ugwuanyi (2014), found no gender difference in the performance of male and female students in school mathematics. Contrary to these reports, Uduosoro (2011) and Onah (2014), found that female students performed better than male students while exposed to longitude and latitude, mensuration and 3-dimensional mathematics instructional materials respectively.

To the researchers knowledge there are limited studies on the effect of globe game on students' achievement and retention in longitude and latitude. In view of the limited studies the researchers consider it necessary to explore the efficacies of globe game on students' achievement and retention in longitude and latitude.

\subsection{Objective of the Study}

The main purpose of the study was to find out the effect of Globe Game on students' achievement and retention in longitude and latitude in Senior Secondary II students' mathematics. The study specifically determined:

- $\quad$ The effect of Globe Game on students' achievement in longitude and latitude.

- $\quad$ The effect of Globe Game on students' retention in longitude and latitude.

- $\quad$ The effect of Globe Game on male and female students' mean achievement in longitude and latitude.

- The interaction effect of gender and instructional approach on students' achievement in longitude and latitude

\subsection{Scope of the Study}

The study was carried out in Nigeria to find the effect of globe game on students achievement and intention in longitude and latitude. The study is delimited to the content area of longitude and latitude for Senior Secondary II students' mathematics curriculum content.

\subsection{Research Questions}

The following research questions guided this study:

1. What is the effect of the Globe Game on students' achievement in longitude and latitude?

2. What is the effect of the Globe Game on students' retention in longitude and latitude?

3. What is the interaction effect of gender and instructional approach on students' achievement in longitude and latitude?

\subsection{Hypotheses}

The following null hypotheses were tested at 0.05 significant levels for the study;

$\mathbf{H}_{\mathbf{0 1}}$ : There is no statistically significant difference in the mean achievement score of students taught longitude 
and latitude using the globe game approach and those taught longitude and latitude using the conventional approach.

H02: There is no statistically significant difference in the mean retention score of students taught longitude and latitude using the globe game approach and those taught longitude and latitude using the conventional approach.

$\mathbf{H}_{03}$ : There is no statistically significant interaction between gender and method (globe game) on students' achievement in longitude and latitude.

\subsection{Research Method}

\subsection{Design of the Study}

The study employed a quasi-experimental procedure. The reason is because the researcher used intact classes and as such could not achieve random assignment of subjects to treatment and control groups. A pretest -posttest non-equivalent control group design was adopted. Intact classes were used to avoid disruption of normal classes, (Ali, 1998) The researchers manipulated the independent variable; (teaching strategy) and observed the effect on the dependent variables (achievement and retention). The design can be represented thus:

$$
\begin{array}{ll}
\frac{\mathrm{Y}^{\mathrm{b}} \mathrm{X} \mathrm{Y}^{\mathrm{a}}}{\mathrm{Y}^{\mathrm{b}}-\mathrm{x} \mathrm{Y^{ \textrm {a } }}} & \\
\text { Where } & \\
\mathrm{Y}^{\mathrm{b}} \quad=\text { Measurement taken before treatment } \\
\mathrm{Y}^{\mathrm{a}} \quad=\text { Measurement taken after treatment } \\
\mathrm{X} \quad=\text { Treatment (Globe Game Instruction) } \\
-\mathrm{X} \quad=\text { Control (Conventional Approach) }
\end{array}
$$

\subsection{Population of the Study}

The population of the study comprised 1,210 Senior Secondary II students in the public secondary schools. The choice of the public schools is because they all have peculiar students' behavior and use the same curriculum. The SS II students were used for the study because the national curriculum for secondary schools provides that Mathematics must be offered by all the SS II students and longitude and latitude is among the topic to be taught in SS II Mathematics, Federal Ministry of Education (2014).

\subsection{Sample and Sampling Techniques}

The sample size for this study was 284 SS11 students drawn from six secondary schools. The schools were drawn through a purposive random sampling. Three of the drawn schools was assigned to the treatment group while the other three assigned to the control group.

\subsection{Instrument for Data Collection}

The instrument for data collection was Longitude and Latitude Achievement Test (LLAT) . LLAT was used as achievement test to measure students' performance in longitude and latitude and to ascertain the level of degree of retention by students. It consisted of 50 multiple choice items with four (4) options: A, B, C, D. A student is expected to tick only one he/she considered correct answer from the options. The instrument was used for both the pretest and posttest. The items in the pretest were reshuffled and the colour of the paper changed before administering them as posttest. The items were selected from the content area of longitude and latitude.

The LLAT was validated by two experts in mathematics (for content validation) and one expert in Measurement and Evaluation for face validation. Longitude and Latitude Achievement Test (LLAT) was administered to 50 SS II students from outside the schools that were involved. The data obtained was used to calculate the reliability of LLAT using the Kudar-Richardson's formula 20 (K-R-20). A reliability co-efficient of 0.91 was obtained. The data was also used to determine the difficulty and discrimination indices of LLAT.

Before the onset of the treatment, subjects in both treatment and control groups were given the pre-test. After the pre-test the regular mathematics teachers started the treatment in their respective schools. They adhered strictly to the lesson procedure developed from the packages. The treatment group was taught using the Mathematics on the globe game package. To play the game, a coin is tossed to decide the player that takes the first turn or the players should throw a die in turn and whoever obtains the highest number starts the game. The throw should be repeated if there is a tie only for those players involved. A player plays by spinning the disc. When the disc stops rotating usually the pointer should indicate a pair of letters. The player concerned then writes down the coordinates of the positions of the letters as seen on the globe and calculates the distance along the longitude or latitude as the case may be between his initial position and his position on the globe. A maximum of four points should be scored after a play. That is one point each for correct coordinating of the positions for the letters on the globe, and two points for correct value of the distance between the two points. Each pair taken should be cancelled on the letter chart. The game continues in this order until twelve out of 
thirteen pairs of the letters on the disc have been taken. Then, at the end of the game a winner results from comparing two points scored by the players. If the pointer stays on the boundary line after a spin, the player loses his chance and scores no point. Further to this, if the pointer happens to indicate a pair of letters which has already been taken the player is allowed a second chance, and if after spinning a second time the pointer either stays on a boundary line or indicates the same or another pair of letters which has been taken, the player loses his chance, otherwise he is scored accordingly, while the control group was taught using the conventional package. The treatment was conducted during the normal school periods, following the normal timetable of the school. At the end of the treatment that lasted for six weeks, the teachers administered the post-test. Data from the pre and post-tests were used to answer the research questions and test the hypotheses. For retention, the researchers administered the posttest again after one month to ascertain the degree of retention of the students.

1. In constructing a Globe Game, one must first get a spinning plastic board or disc cut to size.

2. Engage the services of designer or artist to produce English Alphabets and mark them in pairs round the disc or board.

3. Construct a pointer that will be located at the middle or center of the disc to service as an indicator that will rotate.

4. It will also include a picture of a geographical globe on which each of the letters of the English alphabet is marked to define a point of intersection of longitude and latitude.

The researchers employed the following measures to ensure that extraneous variables, which may introduce bias or error into the study, were checked appropriately.

(a) Teacher Variable: The researchers organized a pre-experimental conference for all the mathematics teachers that were used for this study. During the conference individual differences of the teachers were identified and remedied. A uniform lesson note was developed by the researcher for teachers in each group. The teachers conducted the experiment in their respective schools. The experiment was regularly monitored by the researcher to ensure that the teachers do not deviate from the agreed pattern of instructions.

(b) Instructional Situation Variable: The researchers issued out the lesson note to the teachers in each group. The teaching was conducted in all classes of SS II in the various schools that were used for this study and not just in the intact classes that were drawn for the study.

(c) Intergroup Variable: Because intact classes were used for this study it is implied that initial equivalence was not achieved for the research subjects in the two groups. In order to control for this inter group differences the experiment employed analysis of co-variance during data analysis.

(d) Hawthorne Effect: The researcher did not select treatment and control groups from the same school to ensure that the students in the treatment and control groups did not mix up at all. This is to reduce the error arising from interaction and exchange of ideas among research subjects from the two groups.

At the beginning of the experiment, the teacher administered the pre-test (for the achievement) to the students. Scores of the students on the pre-test were kept behind for use after the experiment. At the end of the experiment, the post-test for the achievement was administered to the students. For each of the groups; data for the pre-test and posttest were recorded separately. In retention, the same question used for achievement was used with only the numbers changed to ascertain the level or degree of retention of the students.

Research questions were answered using mean and standard deviation while hypotheses were tested using the Analysis of co-variance (ANCOVA) at an alpha level of 0.05

\subsection{Results}

\subsection{Research Questions}

Research Question 1: What is the effect of the Globe Game on students' achievement in longitude and latitude?

Table 1: Mean longitude and latitude achievement scores of students taught longitude and latitude using the globe game approach and those taught with the conventional method.

\begin{tabular}{llll}
\hline Groups & N & Adjusted mean & Std Dev. \\
\hline Treatment Group & 169 & 60.92 & 10.74 \\
Control Group & 115 & 39.08 & 7.77 \\
\hline
\end{tabular}

Summary of the result presented in Table 1 reveals that globe game approach yielded adjusted mean achievement score of 60.93 with a standard deviation of 10.74 while the conventional method yielded adjusted mean of 39.08 and a standard deviation of 7.77 implying that students taught with the globe game approach obtained higher achievement score than those taught with conventional approach. 
Research Question 2: What is the effect of the Globe Game on students' retention in longitude and latitude?

Table 2: Mean longitude and latitude retention scores of students taught longitude and latitude using the globe game approach and those taught with the conventional method.

\begin{tabular}{llll}
\hline Groups & N & Adjusted mean & Std Dev. \\
\hline Treatment Group & 169 & 60.44 & 10.47 \\
Control Group & 115 & 38.48 & 8.36 \\
\hline
\end{tabular}

Summary of the result presented in table 2 reveals that globe game approach yielded adjusted mean retention score of 60.44 with a standard deviation of 10.47 while the conventional method yielded adjusted mean of 38.48 and a standard deviation of 8.36. It is seen that, the globe game approach has higher retention mean score than the conventional approach in longitude and latitude.

Research Question 3: What is the interaction effect of gender and instructional approach on students' achievement in longitude and latitude?

Table 3: Summary of interaction effect of gender and teaching method on students' mean achievement scores in longitude and latitude.

\begin{tabular}{lll}
\hline Groups & $\begin{array}{l}\text { Adjusted means for gender categories } \\
\text { Male students }\end{array}$ & Female students \\
\hline Treatment & 63.53 & 59.00 \\
Control & 37.61 & 40.17 \\
\hline
\end{tabular}

Summary of result presented in Table 3 reveals clearly that there is no interaction between gender and teaching method on students' mean achievement scores in longitude and latitude. Result presented in the table indicated that globe game approach is to the conventional approach at the two level of gender (male and female).

\subsection{Hypotheses}

Ho1: There is no statistically significant difference in the mean achievement score of students taught longitude and latitude using the game approach and those taught longitude and latitude using the conventional approach.

Ho3: There is no statistically significant interaction between gender and Instructional approach on students' means achievement in longitude and latitude.

Table 4: Analysis of Co- Variance for Students Overall Longitude and Latitude Achievement scores by teaching methods and by gender

\begin{tabular}{llllll}
\hline Sources of variation & Sum of squares & DF & Mean squares & F & Sig. of F \\
\hline Covariate & 11748.447 & 1 & 11748.447 & 187.917 & .000 \\
Main Effects & 29295.940 & 2 & 14647.970 & 234.296 & .000 \\
METHODS & 29006.874 & 1 & 29006.874 & 463.967 & .000 \\
GENDER & 271.817 & 1 & 271.817 & 4.348 & .038 \\
2-Way Interactions & 91.978 & 1 & 91.978 & 1.471 & .077 \\
Methods \& Gender & 91.978 & 1 & 91.978 & 1.471 & .077 \\
Explained & 41504.277 & 4 & 10376.069 & 165.966 & .000 \\
Residual & 17442.860 & 279 & 62.519 & & \\
Total & 58947.137 & 283 & 208.294 & & \\
\hline
\end{tabular}

Summary of result in Table 4 reveals that for hypothesis 2 , the alpha level (0.05) is greater than the Sig. of $\mathrm{F}$ (.000). Based on the decision rule the researcher rejects the null hypothesis and conclude that there is statistically significant difference in the mean achievement score of students taught longitude and latitude using the game approach and those taught longitude and latitude using the conventional approach.

For hypothesis 3, summary of result in Table 4 reveals that the alpha level (0.05) is less than the Sig of F (.077). The researchers therefore uphold the null hypothesis and conclude that there is no statistically significant interaction between gender and Instructional approach on students' means achievement in longitude and latitude.

Ho2: There is no statistically significant difference in the mean achievement scores of male and female students taught longitude and latitude using the globe game approach.

Table 5: Analysis of Co Variance for Students Longitude and Latitude Achievement scores for treatment group only by gender

\begin{tabular}{llllll}
\hline Sources of variation & Sum of squares & DF & Mean squares & F & Sig. of F \\
\hline Covariate & 2865.431 & 1 & 2865.431 & 30.127 & .000 \\
Main Effects & 734.981 & 1 & 734.981 & 7.727 & .006 \\
GENDER & 734.981 & 1 & 734.981 & 7.727 & .006 \\
Explained & 3600.412 & 2 & 1800.206 & 18.927 & .000 \\
Residual & 15788.736 & 166 & 95.113 & & \\
Total & 19389.148 & 168 & 115.412 & & \\
\hline
\end{tabular}


For hypotheses 2, table 5 revealed that the alpha level (0.05) is greater than the Sig. of F (.006). We reject the null hypotheses and conclude that there is a significance difference between the mean achievement score of male and female students' taught longitude and latitude using the globe game approach.

\subsection{Summary of Results}

Results revealed that:

- There is statistically significant difference in the mean achievement score of students taught longitude and latitude using the game approach and those taught longitude and latitude using the conventional approach. The mean achievement scores of male students are significantly higher than the mean achievement of female students using the globe game approach.

- $\quad$ There is no statistically significant interaction between gender and Instructional approach on students' means achievement in longitude and latitude. But rather, there is a significance difference between the mean retention scores of male and female students' taught longitude and latitude using globe game.

- $\quad$ There is a significant interaction between gender and instructional approach students' mean retention in longitude and latitude.

\subsection{Discussion}

The results from this study indicated that students taught longitude and latitude using globe game performed significantly better than student' taught using the conventional method. In other words, the experimental group produced higher mean achievement score than the control group taught the same topic using the conventional method. Students in the experimental group of this study advanced in level of understanding as they applied their own understanding of the rules of the game in solving mathematical problems such as the one of longitude and latitude.

The finding of this study is in agreement with the earlier research such as Iji (2013) who supported that mathematical games with its ability to generate fun enhance cognition without stressing the learners. This is also in consonance with the finding of Iji (2010), that mathematical game provides a clear understanding of mathematical rules and principles.

Male students taught longitude and latitude using globe game had mean score slightly higher than the female students taught longitude and latitude with globe game. The game approach should be used for teaching for better understanding and higher achievement by students. Both male and female students benefit more when taught with globe game.

There is no interaction between gender and teaching method on students' mean achievement scores in longitude and latitude. The globe game approach is superior to the conventional approach at the two levels of gender in fostering achievement. Treatment interaction generally implies that different learners with different characteristics may profit more from one type of instructional than from another and that therefore it may be possible to find the best match of learners characteristics and instructional approach in other to maximize learning outcomes or whichever dependent variable that is involved.

One may begin to appreciate the worth of the mathematical game approach both in its superiority over the conventional approach and its ability to accommodate both males and females in fostering achievement in longitude and latitude.

The results from this study indicated that the students in the experimental group obtained higher mean scores in retention and retained more of the longitude and latitude content and concepts taught than those in the control group. The findings of this study are in accordance with that of Iji (2013), who confirmed that the use of globe game enhance students retention in longitude and latitude and in turn improve achievement in mathematics.

\subsection{Conclusions}

From the results obtained in the investigation into the effect of globe game on students' achievement and retention in longitude and latitude. The researcher drew the following conclusions.

1. The globe game approach as a teaching method is significantly better than the conventional teaching method in enhancing students' achievement and retention in longitude and latitude.

2. Though with the globe game approach male show higher achievement and retention than female. The difference in the mean achievement and retention of male and female taught longitude and latitude using the globe game approach is not statistically significant.

3. There is no significant interaction between gender and instructional approach on students' achievement and retention in longitude and latitude. For both males and females, the globe game approach is superior to the conventional approach in fostering achievement and retention in longitude and latitude.

\section{References}

Ali, A. (1998). Strategies issues and trends in science education in Africa. Onitsha: Cape Public international 
Ltd.

Dotun, F. (2015) Mathematical game for teaching simple substitution of values into algebraic expressions. Journal of Issues on Mathematics, 8(1), 97-105.

Ezeamenyi, M.O (2012). Effects of four games on mathematics achievement of J.S.S. Students on some selected topics in mathematics. Nigerian Journal of Functional Education (NAPFED)6, (1), 156-161.

Ezeano, C.A. (2013). Effect of small scale experiment on students' achievement and retention in chemistry. Unpublished Doctoral Dissertation University of Nigeria, Nsukka.

Iji, C. O. (2010). Actualizing mathematics achievement and retention among primary school pupils using interactive logo programming package. ABACUS. The Journal of the Mathematical Association of Nigeria $(M A N), 35(1), 80-90$.

Iji, C. O. (2013). Effect of logo and basic programs on the achievement and retention in geometry of jss students. Unpublished Doctoral Dissertation, University of Nigeria, Nsukka.

National Educational Research and Development Council (2015). Performance of Nigeria secondary school students in public examination GCE/SSCE. Research Report 2, Abuja. NERDC Press.

Nicol, J. (2014) Research on learning and higher education teaching, UCOSDA briefing paper 45 (Sheffield, Universities and Colleges Staff Development Agency).

Odo, L.C. (2012). Enhancement of the integration of computer technology into nigerian secondary school curriculum. Computer Education Research Journal (CERJ), 1(1)93-99

Oldfield, B. (2015). Games in the learning of mathematics. Mathematics in Schools, 20(1).

Onah, E.N. (2014). Effects of indices card and board (INDICAB) - game on the achievement and interest of students in indices. Unpublished MEd Thesis, Department of Science Education, University of Nigeria, Nsukka.

Paulina, M. (2015). Perspectives on the teaching of geometry for the 21st century.

Uduosoro, U.J (2011). Perceived and actual learning difficulties of students in secondary school mathematics. International Multidisciplinary Journal, Ethiopia, 5 (5),2011, 357-366.

Ugwuanyi, C.C. (2014). Effect of algebraic substitution and factorization (ASFAC) games on S.S. students' achievement and retention in algebra. Unpublished M.Ed Thesis University of Nigeria, Nsukka.

West African Examinations Council (2011). Chief Examiner's reports (Nigeria) SSCE, May/June examinations.

West African Examinations Council (2016). Chief Examiner's reports (Nigeria) SSCE, May/June examinations. 